\title{
A RELAÇÃO ENTRE MÉDICOS RESIDENTES E PACIENTES INTERNADOS: RELATO DE EXPERIÊNCIA DA PERCEPÇÃO DE UM ACOMPANHANTE
}

\author{
Rhanica Evelise Toledo Coutinho ${ }^{1}$ \\ Sônia Cardoso Moreira Garcia ${ }^{2}$ \\ Sandro Javier Bedoya ${ }^{3}$
}

\begin{abstract}
RESUMO. A relação entre médico e paciente, objeto desse estudo, é um processo que vem evoluindo desde que o primeiro, o médico, estendeu a mão para um semelhante, com o objetivo de aliviar os males. Trata-se da apresentação de um relato de experiência da relação médico residente e pacientes, vivenciada por um acompanhante de paciente internado em um hospital do interior de São Paulo. Foi realizado um levantamento do estado do conhecimento, o qual mapeou nos periódicos, Revista Psicologia e Saber Social e Revista Brasileira de Educação Médica pesquisas inerentes a proposta desse estudo. Como resultado trazemos o questionamento sobre a formação que os nossos médicos estão recebendo nas suas respectivas universidades, ou seja, se as mesmas têm identificado tais questões e quais as estratégias tomadas para resolver as mesmas, indagamos se estes residentes já, dentro do que consideram como representação ser médico. Foi possível constatar a urgência no fomento ao desenvolvimento de investigações com essa abordagem.
\end{abstract}

Palavras-chave: Representações Sociais; ensino médico; interação médico-paciente; humanidades médicas.

\section{THE RELATIONSHIP BETWEEN RESIDENT PHYSICIANS AND INJURED PATIENTS: EXPERIENCE REPORT OF THE PERCEPTION OF AN ACCOMPANYING PERSON}

\begin{abstract}
The relationship between doctor and patient, object of this study, is a process that has evolved since the first, the doctor, reached out to a similar, with the purpose of alleviating the evils. This is the presentation of an experience report of the resident physician and patients relationship, experienced by a patient inpatient in a hospital in the interior of São Paulo. It was carried out a survey of the state of knowledge, which mapped in the periodicals, Revista Psicologia e Saber Social and Brazilian Journal of Medical Education researches in the proposal of this study. As a result we bring the questioning about the training that our doctors are receiving in their respective universities, that is, if they have identified such issues and what strategies

\footnotetext{
1 Doutoranda em Ciências da Educação - UTAD - Pt. Mestre em Ensino das Ciências da Saúde e do Meio Ambiente - UniFOA. Professora do Curso de Medicina - Tecnologias da Informação e Comunicação e Mídias - UNIFOA .Pesquisadora Colaboradora/ Laboratório de Estudo e Pesquisa na/para a Formação de Professores LAGERES/UFCG - CNPq

2 Doutoranda em Ciências da Educação - UTAD - Pt. Mestre em Ensino das Ciências da Saúde e do Meio Ambiente - UniFOA . Professora do Curso de Medicina - Gestão em Saúde e Bases Humanísticas - UNIFOA .Pesquisadora Colaboradora/ Laboratório de Estudo e Pesquisa na/para a Formação de Professores - LAGERES/UFCG - CNPq 3 Pesquisador em Saúde Pública do Departamento de Epidemiologia e Métodos Quantitativos em Saúde (DEMQS) na Escola Nacional de Saúde Pública Sergio Arouca (ENSP) na Fundação Oswaldo Cruz (FIOCRUZ)
} 
have been taken to solve them, we ask if these residents already, in what they consider as representation to be a physician. It was possible to verify the urgency in the promotion of the development of investigations with this approach.

Keywords: Social representations; medical education; physician-patient interaction; medical humanities.

\section{LA RELACIÓN ENTRE LOS MÉDICOS RESIDENTES Y PACIENTES INTERNADOS: RELATO DE EXPERIENCIA DE LA PERCEPCIÓN DE UN ACOMPAÑANTE}

RESUMEN. La relación entre médico y paciente, objeto de ese estudio, es un proceso que viene evolucionando desde que el primero, el médico, extendió la mano hacia un semejante, con el objetivo de aliviar los males. Se trata de la presentación de un relato de experiencia de la relación médico residente y pacientes, vivenciada por un acompañante de paciente internado en un hospital del interior de São Paulo. Se realizó un levantamiento del estado del conocimiento, el cual mapeó en los periódicos, Revista Psicología y Saber Social y Revista Brasileña de Educación Médica investigaciones inherentes a la propuesta de ese estudio. Como resultado traemos el cuestionamiento sobre la formación que nuestros médicos están recibiendo en sus respectivas universidades, es decir, si las mismas han identificado tales cuestiones y cuáles las estrategias tomadas para resolverlas, indagamos si estos residentes ya, dentro de lo que consideran como de ser médico. Es posible constatar la urgencia en el fomento del desarrollo de investigaciones con ese enfoque.

Palabras clave: Representaciones Sociales; enseñanza médica; interacción médicopaciente; humanidades médicas.

\section{Introdução}

A relação entre médico e paciente, objeto desse estudo, é um processo que vem evoluindo desde que o primeiro, no caso o médico, estendeu a mão para um semelhante, com o objetivo de aliviar os males que, por ventura, estivessem a assolar o corpo, mostrando que era possível contornar, mesmo que temporariamente, a morte derradeira (2015). No entanto, com o avanço da ciência e das considerações a respeito da formação médica, a relação médico-paciente, gradativamente, veio tomando contornos em que a mera solidariedade e humanidade foi cedendo espaço para questões como a comercialização, o tecnicismo e, não raro, dependendo dos métodos aplicados, a indiferença com relação à humanização (CAPRARA; FRANCO, 1999). 
O avanço científico em busca da cura como prioridade torna, segundo tal ótica, desnecessário conhecer o ser da doença pois não é a sua identidade que está sendo tratada e sim a doença e o órgão que acomete. Nesse sentido, podemos pensar sobre como a Teoria Psicanalítica oferece subsídios com os quais poderemos transformar esse estado precário de coisas (MELLO FILHO, 2009).

As Diretrizes Curriculares Nacional (DCNs, 2014) preconizam uma formação médica humanística, crítica e reflexiva, que se estabeleça em diferentes níveis de atenção a saúde, tanto no âmbito individual como no coletivo, e isso, de forma transversal, pautado na responsabilidade social e no comprometimento com a defesa da cidadania, da dignidade humana e da saúde integral do indivíduo.

O tratamento da saúde física tem por objetivo, de forma basicamente científica, combater aquilo que está a afligir o corpo e que, consequentemente, provoca o mau funcionamento possibilitando novos contornos à relação médico-paciente (PIETRUKOWICZ, 2001). E é justamente o que este artigo busca discutir a partir de um relato de experiência de uma breve passagem, de um dos autores, enquanto acompanhante de um paciente hospitalar que se convalescia de uma enfermidade respiratória grave, ou seja, o estudo delineia a relação entre médicos, mais especificamente, médicos residentes e pacientes.

Este artigo tem por intuito apresentar as impressões adquiridas em um certo espaço médico-hospitalar, referente aos efeitos da indiferença dentro da relação entre médico e paciente, e como este último se sente quando se percebe apenas um espaço de estudos oferecendo problemas a serem solucionados e não sendo percebido como um ser humano a ser ajudado, dentro dos princípios da solidariedade entre iguais.

O despertar para tal ação ocorre depois de observadas certas posturas que per apesar de serem consideradas banais e sem importância, na opinião de alguns, no processo da construção de um relacionamento com um determinado fim, no caso a busca pela saúde, acreditamos que com o tempo pode vir a desenvolver barreiras psicológicas desnecessárias que, de forma sutil ou não, podem vir a dificultar o processo da recuperação plena da saúde para aqueles que se sentem impactados por tais posturas.

Após perceber que tais posturas se repetiam a ponto de se tornarem cotidianas surgiu o questionamento sobre quais representações estes jovens residentes estão 
tomando para si sobre o exercício da medicina e de que forma o meio acadêmico vem discutindo esse tema.

Para tanto, com a finalidade de interpretar as questões ligadas à aplicabilidade das práticas de saúde observadas no período em que o relator permaneceu na instituição médica onde ocorreu tal observação, optamos pelo uso da Teoria das Representações Sociais, de Serge Moscovici (2003), que discute o significado do tema demonstrando que o mesmo se inscreve a partir de um referencial de pensamento preexistente sendo, com isso, atrelados a valores, tradições, crenças e imagens do mundo e da existência (SILVA, 2010).

Visando mapear no cenário acadêmico, especificamente nos meios em que são desenvolvidas pesquisas que tratam da Teoria das Representações Sociais, Ensino Médico e Humanidades Médicas, estudos que pudessem trazer discussões acerca da temática delineada para este estudo, embora acredita-se que pouco vem sendo abordado sobre a relação médico residente e paciente.

Podemos iniciar citando, de acordo com o relato, a ausência de certas posturas como um simples cumprimento, ou uma sutil preocupação pelo outro, mesmo sendo um desconhecido e não estando na lista de pacientes a serem tratados. Dentre os grupos citados chamou a atenção os jovens médicos residentes que após serem observados atentamente, cada vez que adentravam o espaço em que se encontrava o relator, ele percebia-se que só se dirigiam aos pacientes que estavam "obrigados" a tratar, enquanto outros, que se encontravam no quarto, eram ignorados até mesmo com a ausência de um simples cumprimento.

Nesse sentido, o estudo se justifica por tratar de um tema de extrema relevância para os cenários das escolas de medicina no contexto do ensino das Humanidades Médicas, uma vez que, essa abordagem é preconizada pelas Diretrizes Curriculares Nacionais (DCNs, 2014).

\section{Teoria das representações sociais: humanismo no ensino médico}

No transcorrer da análise do presente tema, como método para compreender as questões observadas dentro do universo em que subsistiu o acompanhamento do paciente, utilizou-se, como instrumento de compreensão desta vivência, a Teoria das 
Representações Sociais com o objetivo de interpretar a realidade social a partir de uma visão crítica de um momento histórico específico.

Para fundamentar a articulação crítica desta vivencia nos ancoramos em representantes como Serge Moscovici e Denise Jodelet, cujo o conceito sobre o assunto podemos encontrar em vários trabalhos, como o de Rafael Augustus Sêga (2000) - O Conceito de Representação Social nas obras de Denise Jodelet e Serge Moscovici, entre outros.

Em um breve histórico sobre Representações Sociais, acreditamos que Moscovici, em um resgate do significado do termo Representação Social, citado inicialmente na sociologia por Émile Durkheim (SÊGA, 2000) utiliza-se de tal método como meio de se fazer leitura dos enfrentamentos vivenciados na sociedade em seus diversos aspectos, principalmente após a Segunda Guerra Mundial onde observamos desdobramentos ideológicos ocorridos que se tornarão, juntamente com os interesses geoestratégicos, a base a Guerra Fria (VICENTINO; DORIGO, 2011).

Mas acreditamos que Moscovici não tinha por objetivo exclusivo repensar, dentro de uma visão política, o conflito entre o mundo capitalista e socialista, no que se refere aos macros confrontos, como por exemplo, o processo de descolonização afroasiática ou conflitos beligerantes ocorridos em regiões como a Coréia (1950-1953) e o Vietnã (1955 a 1975). Na verdade, como é percebido na coletânea de suas obras voltadas para a área da sociologia e psicanalise que demonstram sim confrontar, dentro de um universo sócio cultural específico, as relações aparentemente contraditórias, mas que na forma de suas interações tornam-se coerente a partir dos eixos sociais que as sustentam, como observadas por meio da psicologia social, um melhor entendimento das reações humanas dentro desta nova realidade (SÊGA 2000).

E trilhando por esta percepção constatamos que as relações ocorrentes dentro de espaços determinados onde grupos com informações e formações distintas alimentamse, a partir de suas características próprias, em movimento de fluxo e refluxo em que o indivíduo, presente dentro do grupo, a partir de suas características pessoais colabora para construção das relações que permeiam o grupo e vice-versa, pois acaba alimentando suas próprias características pelo o que recebe de influência sócio cultural do grupo. Sobre este aspecto nos diz Rafael Augusto Sêga

RPI Revista de Pesquisa Interdisciplinar, Cajazeiras, v. 3, n. 1, 87-106, jan/jul. de 2018. 
As representações sociais se apresentam como uma maneira de interpretar e pensar a realidade cotidiana, uma forma de conhecimento da atividade mental desenvolvida pelos indivíduos e pelos grupos para fixar suas posições em relação a situações, eventos, objetos e comunicações que lhes concernem (SÊGA, 2000 p.128).

Como já percebido, a partir da citação de Rafael Augusto Sêga (2000), as obras de Moscovici, relacionadas a Teoria das Representações Sociais, foram e continuam estudadas por diversos acadêmicos, como por exemplo o trabalho de Angela Arruda (2002) que apresenta outra definição interessante a partir do seu estudo que tem como tema Teoria das Representações Sociais e Teorias do Gênero (2002), em que faz breve análise da obra La Psychanalyse, son image, son public, de Moscovici. Neste estudo ela afirma que:

A Teoria das Representações Sociais. TRS operacionalizava um conceito para trabalhar com o pensamento social em sua dinâmica e em sua diversidade. Partia da premissa de que existem formas diferentes de conhecer e de se comunicar, guiadas por objetivos diferentes, formas que são móveis, e define duas delas, pregnantes nas nossas sociedades: a consensual e a científica, cada uma gerando seu próprio universo. A diferença, no caso, não significa hierarquia nem isolamento entre elas, apenas propósitos diversos. (ARRUDA, 2002 p.129-130)

Com isso, podemos afirmar a partir de Arruda (2002) e Sêga (2000) que as representações sociais são construídas a partir das práticas cotidianas e da experiência pessoal que o indivíduo acumula ao longo da sua existência e que, entre outros aspectos, fazem parte do senso comum.

E dentro desta linha de pensamento acreditamos, que se deva estimular, estudos referentes a quais as Representações Sociais estão ligadas à interação médico e paciente, ou seja, particularmente como os médicos residentes atualmente entendem essa interação e principalmente, em quais valores estão estruturados a maneira utilizada para tratar seus pacientes, sujeito da doença, e ainda, como interagem, em seus espaços de trabalho, com aqueles que não são considerados pacientes.

Nesse contexto, faz-se necessário compreender como se desenvolvem e emergem as representações sociais e a esse processo Moscovici (1978) da o nome de objetivação e ancoragem. Conforme o autor nos ensina, a objetivação "é o momento em que o abstrato se transforma em concreto, cristalizando as ideias e tornando-as 
objetivas" (MOSCOVICI, Ano, 1978). Já ancoragem é o processo de classificar e dar nome alguma coisa que não é classificada, ou seja, transformar algo estranho em algo comum e familiar (PEIXOTO; FONSECA; OLIVEIRA, 2013).

Portanto, não podemos esquecer que diante do saber comum, a objetivação acontece quando a compreensão dos conceitos científicos, aqueles que explicam as dinâmicas sociais em que o indivíduo é inserido, passa para uma ideia mais simples e palpável.

Porém, não se pode negar que a concretização do saber ocorrerá de forma diferenciada de indivíduo para indivíduo, pois cada um se apropriará das vivências sociais para traduzir os conceitos a partir de suas experiências anteriores.

Com isso, dentro da representação do ser médico, alguns jovens residentes se identificam profissionalmente de acordo com a definição que Max Weber, que trata sobre profissionalismo a partir da sua teoria burocrática, que diz sobre a Hierarquia da autoridade.

\begin{abstract}
A burocracia e uma organização que estabelece os cargos segundo o princípio da hierarquia. Cada cargo inferior deve estar sob o controle e supervisão de um posto superior. Nenhum cargo fica sem controle ou supervisão. Dai a necessidade da hierarquia da autoridade para definir as chefias nos vários escalões de autoridade. Todos os cargos estão dispostos em uma estrutura hierárquica que encerra privilégios e obrigações, definidos por regras especificas. A autoridade - o poder de controle resultante de uma posição - e inerente ao cargo e não ao individuo que desempenha o papel oficial (CHIAVENATO, 2008, p.37-38).
\end{abstract}

Portanto, a discussão sobre as Representações do exercício da profissão na área de saúde não poderia ser de outra forma, senão a partir dos futuros profissionais desta área e demais elementos que a vivenciam em seus respectivos cotidianos, e principalmente, que tipo de formação estão tendo quando se trata de exercer a ciência médica para a busca da saúde de um ser humano.

\title{
Ensino médico
}

O início do século XIX marca, acentuadamente, o tempo em que a medicina sob o olhar crítico de sua história passada e para justificar sua originalidade, mostra-se como medicina científica. Para marcar essa transformação que se mostrou fundamental na estruturação e organização do conhecimento médico e de sua prática, apresentamos 
Michel Focault que vem demonstrar que a cisão que se processou no saber médico não se deve, essencialmente, a um refinamento conceitual e nem à utilização de ferramentas técnicas mais potentes, mas sim, se deve a um deslocamento, uma mudança ao nível de seus objetos, conceitos e métodos. Para Focault (2008, p. 61) "Nos tempos passados a arte da medicina era ensinada na presença de seu objeto e os jovens aprendiam a ciência médica no leito do doente".

Desta forma, percebemos que a mutação que permitiu e ainda nos dias atuais permite, que a beira do leito do doente seja um cenário do campo de investigação e de discursos científicos, não se deu por um milagre a medicina como ciência clínica surgiu com sua possibilidade histórica somada ao domínio de sua experiência e à estrutura de sua racionalidade (FOCAULT, 2008).

Nesse sentido, acreditamos que a representação de médico, ainda está ligada ao conceito histórico e anterior ao século XIX onde a figura do médico era associada ao divino. Com o surgimento da clínica surge uma nova perspectiva onde o objeto de estudo da medicina passa a ser o sujeito vivo.

Para uma parte significativa da sociedade, o ser médico relaciona-se a um empoderamento ilimitado o que é erguido por título que o designa enquanto profissional que se constitui a partir de esquemas práticos e que, os definem enquanto ser da medicina. Para Sacristán (1995, p.80) sobre este aspecto diz “[...] esquema prático é uma rotina; um esquema estratégico é um princípio regulador a nível intelectual e prático, isto é, uma ordem consciente da acção”.

Vários são os autores que trabalham o ensino da Ciência e da Saúde. Entre eles podemos citar Gazzinelli et al (2005, p. 201) no trabalho intitulado Educação em saúde: conhecimentos, representações sociais e experiências da doença, em que analisam o saber ciência e saúde. Neste trabalho eles afirmam que

\footnotetext{
O princípio de se educar para saúde e para a ambiente parte da hipótese de que vários problemas de saúde são resultantes da precária situação educacional da população, carecendo, portanto, de medidas "corretivas" e/ou educativas. Tal hipótese levou à utilização, na prática pedagógica em saúde, de estratégias ligadas à ideia de que a apreensão de saber instituído sempre leva à aquisição de novos comportamentos e práticas. Assim, comportamentos inadequados do ponto de vista da promoção da saúde são, então, explicados como decorrentes de um déficit cognitivo e cultural, cuja superação pode se dar por meio de informações científicas e saberes provenientes do exterior.
}

RPI Revista de Pesquisa Interdisciplinar, Cajazeiras, v. 3, n. 1, 87-106, jan/jul. de 2018. 
Os referidos saberes provenientes do exterior referem-se, também, aos temas humanísticos que são disseminados no ensino médico. Nesse sentido, pensamos ser as DCNs (2014), um instrumento norteador que oferece arcabouço o qual funcionará como validação para as transformações dentro da graduação dos cursos de medicina. Desta forma, entendemos que o futuro médico ao se alimentar de tais diretrizes, entre elas as humanísticas, insere na sua essência um esquema estratégico que por si só, facilitará a regulação do comportamento e da ação e isso, na relação médico e paciente.

Nessa esteira de pensamentos alcançamos a realidade onde tais profissionais, oriundos do novo ensino médico, podem ser considerados referencias de representatividade social, e no recorte desse estudo, enfatizamos o profissional médico residente. E isso, visto que em instituições de ensino médico encontramos elementos de diversos matizes sociais, econômicos e culturais. Logo, visões heterogêneas não são exceções, mas sim, a própria regra, reforçando as relações de trocas entre os sujeitos e o seu meio, e vice-versa.

A priori, como caminho para se entender a formulação das representações que constitui o exercício da medicina para estes residentes, acreditamos que seria interessante apontarmos como o ensino da saúde em medicina está sendo administrada nas instituições acadêmicas em que estão se formando os novos residentes médicos.

Como orientação de estudo, sobre o assunto, temos o trabalho de Moreira et al (2009) intitulado "A Saúde no Livro Didático de Ciências: Um Exercício de Análise", que trabalha a problematização dos conceitos de saúde e como estes são vistos. Os autores, ao discutirem tal aspecto, demonstram a importância do ensino enquanto agente formativo de indivíduos voltados para as práticas de saúde "[...] A escola aparece ocupando um papel importante na tarefa de formar indivíduos com capacidade de autocuidado, entendendo a saúde como um direito e responsabilidade pessoal e social" (MOREIRA ET AL, 2009, p.6).

Queremos crer que como as instituições de ensino médico não são, necessariamente, um espaço homogêneo e assim, por essa heterogeneidade que se levanta, pensamos ser possível perceber a dificuldade de fazer ciência em uma sociedade múltipla e diversa, aqui representada, por acadêmicos de medicina e ainda, entender de forma heterogênea um conceito que ainda é apresentado de forma homogênea. 
Acreditamos, desta forma, que posteriormente, nos cenários de diagnóstico, tratamento e possível ou não cura, estes mesmos acadêmicos enfrentarão situações semelhantes ao terem que interagir com uma multiplicidade de características sociais assinaladas, tanto nos seus pares, quanto em seus sujeitos de atenção à saúde, multiplicidades essas que se apresentarão, rotineiramente, na vida profissional dos futuros residentes e ainda, que ditarão o ritmo e o andamento das relações.

\section{Humanidades médicas e interação médico-paciente}

Historicamente as humanidades médicas apareceram em consonância ao desenvolvimento do campo das ciências humanas e sociais em saúde e também, tendo com elas inúmeros pontos de intercessão.

As ciências humanas e as humanidades têm ampliado seu status na área da saúde e vem ao longo da história alcançado um protagonismo que se percebe com o aumento de produção de conhecimento e de práticas voltadas para a saúde e para a medicina. Rios (2015, p. 22) afirma que

Na medicina a irredutível dimensão (e extensão) do humano se impõe em sua prática na forma de captura do médico para dentro da vida das pessoas, como parte inerente do exercício de sua profissão e arte, ou mesmo à sua revelia. Entretanto, o modo de lidar com tal presença muda conforme valores culturais e direcionamentos sociais da profissão em diferentes épocas históricas.

Traremos aqui para o palco de nossos pensamentos as humanidades médicas inseridas na medicina como cenário que se mostra lado a lado no tempo em que também se constitui o campo das ciências humanas e sociais em saúde. A medicina pode ser compreendida entre ciência e arte, com uma constituição de equilíbrio proporcional do qual não pode se furtar, dessa forma, Basco (2012, p.10) afirma "[...] que ser médico é, antes de tudo equilíbrio desses componentes que são a razão da existência da medicina". Podemos entender que este equilíbrio somente se efetiva a partir de uma reflexão que vai promover a referida harmonia proporcional, e isso, nos permitirá uma visão personalizada não só da doença, mas também do sujeito da doença.

Nesse caminho como cerne das discussões trazemos as humanidades médicas voltadas às relações humanas no contexto da intersubjetividade, ou seja, na interação 
entre sujeitos e suas relações no âmbito da saúde, deslizando entre o otimismo e o cientificismo tecnológico. Nessa linha de pensamento não podemos ignorar o momento do encontro médico e paciente, que para Porto $(2015$, p. 1) "é essencial cultivar o componente ritualístico da consulta: o médico e paciente, um ao lado do outro".

E como este trabalho se refere principalmente a médicos residentes, os quais podemos dizer que ainda se encontram na condição de estudioso do ensino médico, reforça-se a interação do cientificismo tecnológico, estimulando o otimismo a partir da possibilidade de não auxiliar um semelhante que se encontra enfermo, mas sim solucionar um problema que irá significar um avanço científico em suas carreiras médicas.

Com isso, a representação apresentada pelos médicos residentes é a partir do relato de experiência aqui proposto é a de uma marcante dificuldade em interagir com esta multiplicidade de características, dos sujeitos envolvidos direta e/ou indiretamente no processo de cuidado em saúde, pois não estamos nos referindo aqui apenas aos pacientes, mas também a colegas de trabalho de outras categorias como por exemplo enfermeiros(as), copeiros(as), administradores(as), faxineiros(as), etc.

Portanto, no que se refere a esta breve análise, que é a proposta de se buscar entender o comportamento dos médicos residentes, pode-se afirmar que, dentro das dinâmicas sociais em que esses profissionais se vêm inseridos, os mesmos, embora tenham em mãos instrumentos de linguagem mais abrangentes do que o vivenciado na linguagem escrita, a que se considerar uma formação médica mais humanista volta para temas em humanidades médicas em currículos do ensino médico.

Com esse fim, sugerimos o estudo de Oliveira e Egry (2000), no trabalho "A Historicidade das Teorias Interpretativas do Processo Saúde-Doença" em que concebem as diversas formas de como foram sentidas e, consequentemente, interpretadas as doenças ao longo da História da humanidade. Porém o que se dá na contemporaneidade é o processo de total despersonalização que o paciente, ao ser hospitalizado, sofre. Se vê despossuído de seu próprio nome, sendo levado à adotar como sua identidade seu número de leito ou o nome da patologia que o acomete (paciente do 103, paciente com câncer de mama). Estamos diante do estigma de doente-paciente, que se confirma nas palavras de Oliveira e Egry (2000, p. 10) relatam que "Ao longo da história, foram sendo forjadas diferentes teorias interpretativas sobre o processo saúde-doença, como 
consequência da atividade racional humana na busca de inferências causais para a doença".

Com isso, acreditamos, a partir desta breve leitura a respeito do material supracitado, criar um espaço de discussão e reflexão sobre o exercimento do ser profissional da área de saúde, pois acreditamos, no que se refere a busca de soluções para as doenças, as mesmas ainda estão restritas a práticas de pesquisa tecnológica, ou seja, o estudo de diagnósticos provocados por doenças de origem alheia a vontade humana, deixando, no entanto, de fora ou no mínimo negligenciada, as doenças motivadas unicamente pela falta de afeto e solidariedade humana.

A situação de hospitalização passa a ser entendida como preceptora de outras tantas situações invasivas e abusivas na medida em que não se leva em consideração os limites, os desejos e os direitos da pessoa hospitalizada e de seus familiares.

\section{Caminho metodológico}

O estudo foi estruturado metodologicamente por meio das Dimensões da Pesquisa Acadêmico-Científica propostas por Novikoff (2010), método que viabiliza a organização do pensamento científico, ou seja, a pesquisa se estrutura em cinco dimensões, sendo elas: a Epistemológica, na qual são apresentados o objeto de estudo, a problematização, os objetivos, hipóteses e a justificativa do estudo; a Teórica que apresenta toda ancoragem da pesquisa, a Técnica que delineia as metodologias utilizadas no desenvolvimento da proposta; a Morfológica, onde são apresentados os dados encontrados em forma de texto, gráficos, figuras e outros; e por fim a dimensão Analítico-conclusiva onde os autores entrelaçam o conhecimento teórico com as informações obtidas, visando atender as questões apresentadas na primeira dimensão por meio de análise comparativa ou crítica.

Trata-se de um relato de experiência vivenciado por um dos autores, que apresenta observações do período em que acompanha um ente internado em hospital do interior do Estado de São Paulo, Brasil. As ponderações aqui apresentadas têm como recorte a relação médico paciente, tanto pelos profissionais experientes quanto e, principalmente, pelos jovens médicos residentes. 
Com isso, acreditamos que a partir da TRS torna-se possível fazer análise mais específica, atendo-se à leitura do pensar saúde e os impactos causados nas interações sociais vivenciadas no período ora citado, após observar atentamente a movimentação hospitalar em seus diversos níveis, no caso, setor de limpeza, alimentação, enfermagem e por fim, na área médica, sujeito da doença e o sujeito da doença (SIMONETI, 2004). Visando ancorar o relato desenvolvido, foi realizada pesquisa bibliográfica do tipo mista $^{4}$ com objetivo de ancorar os conceitos basilares como Teoria das Representações Sociais (MOSCOVICI, 1966; JODELET, 1991; NOVIKOFF, 2014).

A ancoragem do estudo traz também os temas, Ensino Médico (DCNs, 2014; FOCAULT, 2008; SACRISTÁN, 1995; GAZZINELLI ET AL, 2005; MOREIRA ET AL, 2009) e Humanidades Médicas (BLASCO, 2012; RIOS, 2015; OLIVEIRA, EGRY, 2000; PORTO, 2015) de forma descritiva, que Cervo, Bervian e Da Silva (2007, p. 62) define como

Estudos descritivos: trata-se do estudo e da descrição das características, propriedades ou relações existentes na comunidade, grupo ou realidade pesquisada. Os estudos descritivos, assim como os exploratórios, favorecem, na pesquisa mais ampla e completa, as tarefas da formulação clara do problema e da hipótese como tentativa de solução. Comumente se incluem nesta modalidade os estudos que visam identificar as representações sociais e o perfil dos indivíduos e grupos, como também visam a identificar estruturas, formas, funções e conteúdos.

Foram realizados dois Levantamentos do Estado do Conhecimento (ROMANOWISK; ENS, 2006) sendo delimitado como primeiros lócus de pesquisas a Revista Psicologia e Saber Social, em artigos teóricos publicados na Revista Psicologia e Saber Social, da Universidade do Estado do Rio de Janeiro - UERJ (http://www.psisabersocial.uerj.br/), entre os anos de 2012 a 2017, tendo como indexadores de busca os termos "Representações Sociais e Ensino Médico; Representações Sociais e Humanidades Médicas".

Como segunda fonte de coleta de dados, buscamos na Revista Brasileira de Educação Médica (http://www.scielo.br/scielo.php?script=sci_serial\&pid=01005502\&lng=pt), periódico da Associação Brasileira de Educação Médica, único da

\footnotetext{
4 "abordagem de multi-método é aquela em que o pesquisador tende a basear seus pressupostos em campos pragmáticos. Emprega estratégias que envolvem a coleta de dados tanto simultaneamente ou sequencialmente para melhor entender os problemas de pesquisa. A coleta de dados envolve tanto informações numéricas quanto informações textuais" (CRESWELL, 2010, p.20).
}

RPI Revista de Pesquisa Interdisciplinar, Cajazeiras, v. 3, n. 1, 87-106, jan/jul. de 2018. 
América Latina dedicado a publicações voltadas para o ensino médico, com periodicidade trimestrais, a revista que disponibiliza trabalhos científicos em três idiomas, sendo eles: português, inglês e espanhol. Optamos pela coleta de dados no mesmo período, ou seja, de 2012 à 2017, nesse caso usamos como indexador de busca os unitermos "Ensino" "Representações Sociais" e "Humanidades".

\section{Relato de experiência: médicos residentes e pacientes - interações preocupantes}

Nos dez dias em que o um dos autores acompanhou o trabalho de residentes médicos, em visita ao quarto onde o paciente estava internado, foi observado que alguns deles pouco ou quase nunca lançavam mão de instrumentos de socialização com o paciente, como por exemplo, um simples bom dia, ou a demonstração de interesse pela pessoa e não apenas pela doença.

Acreditamos que tal situação ocorria por não acharem necessário dominar os mesmos, ou uma questão mais preocupante que é a de se enxergar como uma casta a parte dentro do espaço de saúde em que exerce a sua profissão recentemente conquistada, com isso, mantendo uma impessoalidade para com os pacientes tratados.

O hospital, em que ocorreu a vivência, localizado no interior do Estado de São Paulo, foi cenário, do relato de experiência aqui trazido, sendo tido como referência no que se refere ao tratamento das enfermidades. A instituição conta com equipes altamente treinadas, inclusive recebendo capacitação na própria instituição, informação essa, obtida no site do hospital.

De fato, foi observado que os enfermeiros possuíam técnicas baseadas em performances de trabalho peculiar, somada à maciça presença de médicos residentes, que, por sua vez, ali se encontravam perfazendo plantões, os quais são exigências para o cumprimento de requisitos referentes as suas respectivas especializações.

Foi neste hospital que o relator ingressou como acompanhante, portanto, como sujeito na doença, passando a conviver com a rotina de visitas de enfermeiros, para ministração de medicamentos, manutenção da estrutura de hospitalização do paciente, e ainda, contando com a presença dos ASGs (auxiliar de serviços gerais) que são responsáveis pela higienização do espaço hospitalar. Além disso, a instituição conta 
também com os serviços de hotelaria hospitalar, que pontualmente forneciam entre outras refeições para pacientes e acompanhantes.

Nessa mesma esteira de pensamento, referimo-nos aqui, à presença fundamental de médicos e residentes médicos que, se faziam presentes os primeiros, os médicos como preceptores liderando um processo de tratamento juntamente com o de ensino e aprendizagem voltado para os residentes que, por sua vez deveriam sorver os conhecimentos juntamente com os exemplos dos experientes profissionais.

A observação a respeito desta e outras questões ocorreram no quarto em que o paciente internado dividia com e um outro paciente que padecia de doença desconhecida, a qual muito chamou a atenção do relator, e isso, pelo humor alegre e espirituoso diante de sua inconveniente enfermidade, sendo ao longo dos dias em que o mesmo passou por esse período no hospital, uma companhia bem-humorada e acima de tudo solidária quando se fazia necessária ajuda.

No entanto, com o passar dos dias o relator começou a observar algumas situações que despertaram nele, certo incomodo, principalmente como ser humano, no que se refere a indiferença de alguns médicos residentes para com os pacientes que não eram institucionalmente acompanhados por eles.

Não raro, quando a equipe do médico responsável por outro paciente, que dividia o quarto com o parente do relator, entrava para se dirigir ao mesmo, excetuando o médico chefe, que sempre se apresentava muito simpático os cumprimentando e, com isso, demonstrando ter uma postura humanística que extrapolada a sua experiência adquirida em bancos acadêmicos, os demais, na maioria jovens residentes, ignoravam o relator acompanhante juntamente com o paciente, como se eles não existissem ali naquele espaço de exercício para o tratamento da saúde.

Esta postura, com o passar do tempo, passou a gerar um sentimento de angústia e consequentemente distanciamento da confiança entre médico e paciente, pois a pergunta que começou a se passar na mente do relator era: qual a representação do ser médico para estes jovens residentes?

Dentro desta perspectiva ele não observou, em momento algum, o esforço por parte de alguns residentes, no local em que ele se encontrava, em promoverem uma relação de trocas entre os indivíduos que não se relacionassem aos interesses deles, mesmo que fosse para dizer um simples "bom dia". 
O relator observou, também nos residentes que tratavam tanto o seu enfermo internado como o rapaz que dividia o quarto com ele, um distanciamento que trouxe a percepção de um certo desconforto emocional pela total ausência de interação materializada na falta de falas tão simples como: "tudo bem com você"?

Acreditamos que esta pergunta não é feita no geral por aproximar demais as pessoas e esse não é o objetivo do residente com o seu paciente. Ele está interessado apenas na solução do malefício que aflige o mesmo. Por isso pergunta-se: "como você está passando hoje?" Com isso, pelo que foi observado a relação fica restrita apenas ao tratamento da doença e nada mais.

\section{Levantamento do estado do conhecimento: representações sociais e ensino médico}

Por meio do Levantamento do Estado do Conhecimento, realizado entre os anos de 2012 à 2017 em três lócus de pesquisa, sendo eles: a Revista Psicologia e Saber Social e Revista Brasileira de Educação Médica, e tendo como indexadores os termos: Representações Sociais e Ensino Médico; Representações Sociais e Humanidades Médicas.

A Revista Psicologia e Saber Social, disponível no link <http://www.psisabersocial.uerj.br/>, disponibiliza trabalhos científicos em quatro idiomas, sendo eles em português, inglês, francês ou espanhol. Com abordagem em temas relacionado ao pensamento e conhecimento sociais, no contexto da psicologia social, temas afins e de campos de intervenção social. Como resultado foram encontrados 121 trabalhos (artigo teórico ou estudo empírico). Desses, apenas 16 faziam de alguma forma, referência à área de saúde e nenhum estudo apresentou um desses unitermos "Representações Sociais e Ensino Médico" e "Representações Sociais e Humanidades Médicas" delimitados para o estudo.

Com relação a Revista Brasileira de Educação Médica, foram encontrados entre os anos de 2012 à 2017, um total de 406 publicações de pesquisas, dentre essas, 81 abordavam a temática ensino, três abordavam as representações sociais e 13 contemplavam temas humanísticos, o que nos chamou a atenção e que dentre os estudos encontrados por meio dos unitermos definidos, nenhuma investigação trazia em sua 
essência uma abordagem voltada para o relacionamento humanizados entre médicos residentes e seus pacientes.

\section{Considerações finais}

Após a vivência descrita chegamos ao ponto em que um fator primordial está cada vez mais visível no espaço hospitalar, seja ele público ou privado, que é o distanciamento entre médico e paciente no que se refere a interação social além da doença que estabeleceu a ligação entre ambos. Uma ligação que não nasceu de forma espontânea, e sim, forçada estabelecida a partir de uma relação burocrática e, dependendo do caso, mercadológica. Relações assim tem por base a impessoalidade onde, segundo Weber o poder de cada pessoa está relacionado ao cargo que ocupa e consequentemente determinando tanto a forma de obediência como submissão

Consequentemente o impacto que tal relação causa faz do espaço hospitalar, por mais bem estruturado que seja, um ambiente opressivo e angustiante onde o tanto o sujeito doente, quanto o sujeito da doença se sintam inseguros quanto aos métodos de cura adotados e até mesmo as esperanças (falsas ou não) que os tratamentos venham a oferecer.

Nos questionamos sobre a formação que os nossos médicos estão recebendo nas suas respectivas universidades, ou seja, se as mesmas tem identificado tais questões e quais as estratégias tomadas para resolver as mesmas, indagamos se estes residentes já, dentro do que consideram como representação ser médico, não se sentem isentos de exercerem o pertencimento a uma comunidade composta por diferentes categorias pelo fato de se perceberem acima delas e não integrados a elas como um elemento que se destaca apenas pela sua especialidade técnica.

Para isso, acreditamos que tais residentes devessem fazer uma releitura sobre a evolução histórica de como se interpreta saúde e doença e como elas devem ser tratadas.

No assunto abordado acreditamos que todos os olhares lançados mesmo sendo incongruentes e desfocadamente percebidos dentro do que se propôs a se observar servem, no entanto, para alimentar o questionamento que deve ser contínuo sobre este assunto, pois a busca da solução sobre doenças que afligem os seres humanos, desde a 
sua criação, não tem prazo de validade, ou seja, pois está inserida no processo da evolução humana que é constante.

Existe um mal que constantemente tem de ser arduamente combatido, pois ele é a porta de entrada para a proliferação de diversas mazelas que afligem a humanidade tanto no corpo, quanto da mente e do espírito. A indiferença.

O levantamento do estado do conhecimento nas duas revistas refutou a hipótese quanto a existência de investigações relacionadas a relação humanizada entre médicos residentes e seus pacientes, com os resultados foi possível constatar a urgência no fomento ao desenvolvimento de investigações com essa abordagem.

\section{Referências}

ARRUDA, Angela. Teoria das Representações Sociais e Teorias do Gênero. Universidade Federal do Rio de Janeiro, Cadernos de Pesquisa nº 117, p.127-147, novembro de 2002.

BLASCO, PABLO GONZALES. A arte médica (I): a formação e as virtudes do médico. Revista Médico Brasileira, 2012.

BRASIL, Ministério da Educação. Diretrizes Curriculares Nacionais para os Cursos de Graduação em Enfermagem, Medicina e Nutrição. Parecer CES/CNE 1.133/2001.

CAPRARA, Andrea et al. A relação paciente-médico: para uma humanização da prática médica. Cadernos de Saúde Pública, 1999. Disponível:

https://www.scielosp.org/scielo.php?pid=S0102-

311X1999000300023\&script=sci_arttext\&tlng=en. Acesso: 03/05/2018.

CERVO, Amado Luiz; BERVIAN, Pedro Alcino; DA SILVA, Roberto. Metodologia Científica. $6^{\text {a }}$ ed. São Paulo: Pearson Prentice Hall, 2007.

CHIAVENATO, Idalberto. Administração Geral e Pública. $2^{\mathrm{a}}$ Edição, $4^{\mathrm{a}}$ reimpressão. Rio de Janeiro: Elsevier, 2008.

FOUCAULT, Michel. O nascimento da clínica. $6^{\mathrm{a}}$ ed. Rio de Janeiro: Forense Universitária, 2008.

FRANCO, Maria Laura Puglisi Barbosa, Representações, Ideologia e Desenvolvimento da Consciência, Programa de Estudos Pós-Graduados em Psicologia da Educação da Pontifícia Universidade Católica de São Paulo, Departamento de Pesquisas Educacionais da Fundação Carlos Chagas. Cadernos de Pesquisa. V. 34, n. 121, p.169-186.jan/abr. 204 
GAZZINELLI, Maria Flávia et al. Educação em saúde: conhecimentos, representações sociais e experiências da doença. Cadernos de Saúde Pública, Rio de Janeiro, v. 21. n. 1, jan./fev. 2005.

GIMENO SACRISTÁN, José. Consciência e acção sobre a prática como libertação profissional dos professores. In: NÓVOA, António (Org.). Profissão professor. Porto: Porto Editora, 1995.

homologação publicada no DOU 03/10/2001, Seção 1, p. 131.

MELLO FILHO, Julio; MIRIAM, Burd (org). Psicossomática hoje. Porto Alegre: Artmed Editora, 2009.

MOREIRA, Maria Cristina do Amaral; LIMA, Amanda; SILVA, Marco Antonio Rocha e ; MARTINS, Isabel - A Saúde no Livro Didático de Ciências: Um Exercício de Análise. Programa de Pós-graduação Educação em Ciências e Saúde, Núcleo de Tecnologia Educacional para a Saúde, Universidade Federal do Rio de Janeiro, VII Encontro Nacional de Pesquisa com Educação em Ciências. Florianópolis; 8 de novembro de 2009.

MOSCOVICI, Serge. A representação social da psicanálise. Rio de Janeiro:Zahar, 1978.

MOSCOVICI, Serge. Representações sociais: investigações em psicologia social. Rio de Janeiro, Vozes, 2003.

NOVIKOFF, Cristina. Dimensões Novikoff: um constructo para o ensinoaprendizado da pesquisa. Desafios da práxis educacional à promoção humana na contemporaneidade. Rio de Janeiro: Espalhafato Comunicação, p. 211-242, 2010.

OLIVEIRA, Maria Amélia de Campos; EGRY, Emiko Yoshikawa. A Historicidade das Teorias Interpretativas do Processo Saúde-Doença. Revista da Escola de Enfermagem da USP v.34, n.1. São Paulo, 2000 p.9-15.

PEIXOTO, Ana Cristina Santos; DE OLIVEIRA FONSECA, Hejaine; OLIVEIRA, Ramony MSR. Ancoragem. Cadernos CESPUC de Pesquisa Série Ensaios, v. 1, n. 23, p. 8-12, 2013. Disponível:

http://seer.pucminas.br/index.php/cadernoscespuc/article/view/8297. Acesso: 01/04/2018.

PIETRUKOWICZ, Marcia Cristina Leal Cypriano. Apoio social e religião: uma forma de enfrentamento dos problemas de saúde. Tese de Doutorado. Apresentada à Escola Nacional de Saúde Pública, Fundação Oswaldo Cruz, 2001. Disponível: https://www.arca.fiocruz.br/handle/icict/4610. Acesso: 07/04/2018.

PORTO, Celmo Celeno. O ritual da consulta médica. Revista Médica de Minas Gerais, 2015. 
ROMANOWISK, Joana Paulin; ENS, Romilda Teodora. As pesquisas denominadas do tipo" Estado da Arte. Revista Diálogo Educacional, v. 6, n. 19, 2006.

SACRISTÁN, J. Gimeno. Consciência e acção sobre a prática como libertação profissional dos professores. Profissão professor, v. 2, p. 63-92, 1995. Porto: Editora Porto, 1995.

SACRISTÁN, José Gimeno. Consciência e acção sobre a prática como libertação profissional dos professores. Revista Profissão Professor, v. 2, p. 63-92, 1995. Porto: Editora Porto, 1995.

SÊGA, Rafael Augustus. O Conceito de Representação Social nas Obras de Denise Jodelet e Serge Moscovici. Revista Anos 90. Porto Alegre, no 13, julho de 2000. SIMONETTI, Alfredo. Manual de psicologia hospitalar. São Paulo: Casa do psicólogo, 2004.

VICENTINO, Cláudio; DORIGO, Gianpaolo. História Geral e do Brasil. Volume 3. Ed. Scipione, $1^{\text {a }}$ edição, São Paulo 2011, p. 185-187 